

\title{
Re-Testing Committee Composition Hypotheses for the U.S. Congress
}

\author{
Rodolfo Espino \\ Department of Political Science, Texas A $6 M$ University, \\ College Station, TX 77843 \\ email: espino@polisci.tamu.edu \\ Michael M. Franz \\ Department of Political Science, University of Wisconsin-Madison, \\ Madison, WI 53706 \\ email:mmfranz@polisci.wisc.edu
}

July 31, 2003

\footnotetext{
${ }^{1}$ We are thankful for the support and feedback from participants of the Research Seminar on Voting \& Politics at the University of Wisconsin-Madison and participants at the 2002 Summer Political Methodology Meeting. We are, most of all, grateful to Tim Groseclose and Keith Krehbiel for sharing their data, time, and thoughts with us.
} 


\begin{abstract}
This study replicates and extends Groseclose's (1994) tests of Congressional committee composition hypotheses for the 99th Congress. Using Monte Carlo simulations, he generates hypothetical committee compositions for ten congressional committees. Utilizing various interest group scores for members of the House, he determines the ideological distribution of each committee, with a null hypothesis of random committee assignment. We replicate most of his findings but also argue that these tests were "too random". Instead, we add restrictions in the simulations to account for institutional constraints on the composition of committees: 1) committees are controlled by the majority party; and 2) committees reflect the partisan ratio of the whole House. We also extend the analyses to the 105th Congress to examine any possible changes resulting from the switch in party control. Overall, we find that the constrained tests do not significantly differ from the unconstrained tests and that the alternative hypotheses of committee composition cannot be supported with data from both the 99th and 105th Congresses.
\end{abstract}




\section{Introduction}

Theories of congressional organization have been widely debated. Alternative hypotheses pit partisan explanations of committee organization against the informational roles committees can play in producing "good" public policy. Other theories additionally explore the likelihood that committees reflect (rather than diverge from) floor preferences. Predictably, empirical tests of such hypotheses have produced no scholarly consensus. Groseclose (1994) engages the debate by using a Monte Carlo technique to test alternative hypotheses of Congressional committee organization. By so doing, he imposes few assumptions (and specifically avoids problematic ones) about the ideological distribution of committee and floor members. For example, difference of means tests, often used to evaluate the significance of floor-committee divergence, assume preferences are distributed normally and that the mean scores of a committee and floor are the correct test statistics. Groseclose asserts that the normality assumption is less convincing for small committees and that the median score is more appropriate.

Groseclose begins with a very simple question: are committees in Congress nothing more than random outcomes? In that sense, is there nothing systematic in the organization of Congress? In asking this, he makes a persuasive and straight-forward argument for why Monte Carlo simulations are an alternative and compelling method of re-examining these questions. In testing each hypothesis, he generates 20,000 hypothetical committees for each of ten committees from the 99th Congress. For example, he simulates 20,000 Agricultural committees, each time randomly selecting (without replacement) 43 members (the size of the committee) from the House population. Using different ideology scores for members of the House, which were assigned by a variety of interest groups, he can determine the ideological distribution of each committee. Thus, the unit of analysis is a Committee-Interest Group dyad (e.g., Education Committee and Labor/COPE). He records the median interest group score for the particular committee, producing 20,000 median voter scores. The distribution of these median scores is an emergent property of the simulation and is therefore not assumed a priori. He tests the following hypotheses:

1. The Preference Outlier Hypothesis Weingast \& Marshall (1988) propose that committees are stacked with preference outliers (e.g., representatives with vested interests in agriculture will be on the agriculture committee). The null hypothesis is that members are distributed randomly across committees. For each interest group score, we know the median of the floor and the median of each committee. The committee median can be greater than, equal, or less than the floor median. The hypothesis is whether the committee median is only randomly greater than or less than the floor median. Groseclose examines the proportion of simulated committee medians that are at least as outlying as the actual committee. If that proportion is less than .05, this is evidence against the null.

2. The Opposing Outlier Hypothesis Weingast \& Marshall (1988) propose that each party selects ideological extremists for each committee. For each interest group score, we know the median preference for the floor and for each party. If the party median is 
less than the floor median, Groseclose examines the proportion of simulated partisan members on each committee that are less than the party median. If the party median is more than the floor median, Groseclose examines the proportion of simulated partisan members on each committee that are more than the party median. If the proportion of simulated medians is less than .05, this is evidence in support of this hypothesis.

3. The Representative Committee Hypothesis Gilligan \& Krehbiel (1987, 1989, 199) propose that the difference between the median committee preference and median floor preference should be small because the floor wants committees to be representative of the floor's preferences. If the observed committee median is greater than the floor median, Groseclose records the proportion of simulated committees less than the committee median. 0.5 is subtracted from this value and multiplied by 2 . This excludes all simulated committees below the simulated median but doubles the remaining proportion so as to capture representativeness on either side of the observed committee median.

4. The Representative Democratic Members Hypothesis Cox \& McCubbins (1993) propose that the majority party will place members on committees so as to create committees that are representative of the majority party's preferences. The same test of the previous hypothesis is repeated, but only for the Democratic contingents on the committee. Groseclose tests this hypothesis for the ten committees identified by Cox \& McCubbins, which are selected because they deal with national policy. Cox \& McCubbins do not assert that this hypothesis works for committees that deal with regional or functional policy. To test the hypothesis, Groseclose uses ADA scores for each member.

Illustrations of the significance test involved in each of these four hypotheses are illustrated in Figures 1-4. On some tests (hypotheses 1 and 3), Groseclose does not control for institutionalized majority-minority party splits on Congressional committees. This means that some of the simulations generate committees that are not possible (i.e., more minority party members than majority party members). However, when testing partisan theories of Congressional organization (hypotheses 2 and 4), he does condition his simulations to reflect majority-minority party committee composition. Because of the large Democratic majorities in the 1980s, his tests of the preference outlier and representative committee hypotheses are less likely to produce Republican-controlled committees, but this assumption is less true with the more even partisan split in the 1990s.

An important consideration here is how many "false" committees would be created without at least a minimum condition that committees be controlled by the majority party. To test this with the partisan composition of the House of Representatives in the 99th Congress (253 Democrats, 182 Republicans), we randomly draw 45 members 10,000 times and tabulate the number of times we observe a "false" committee - that is, a committee controlled by the minority party. Under such conditions, 12 percent of the committees created are controlled by the minority party. Whether this has on effect on Groseclose's tests will be discussed later in this paper.

\footnotetext{
${ }^{1}$ The average committee size of the House committees examined by Groseclose is 45 .
} 
Figure 1: Outlier Hypothesis

\section{Outlier Hypothesis}

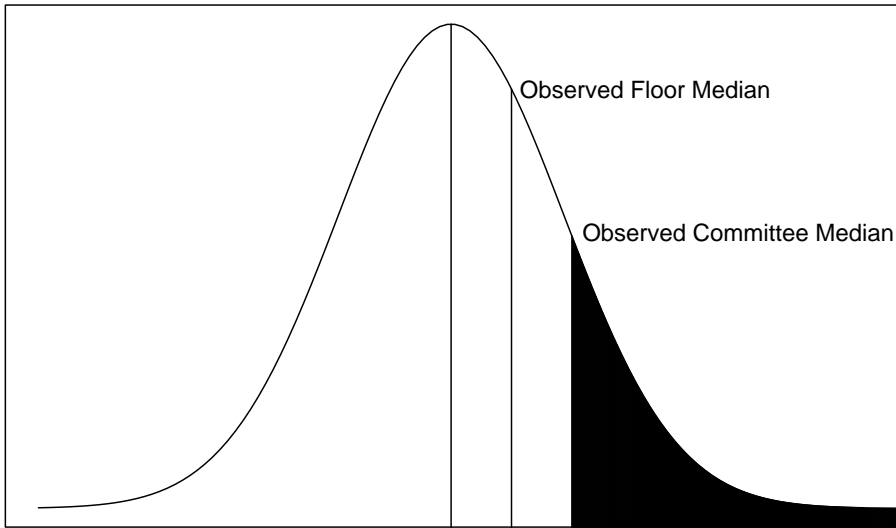

Distribution of 20,000 Simulated Medians

Committees Created Randomly from Entire House

†Source: Shaded sections are the reported p-values in each table. Small p-values indicate support for the Outlier Hypothesis.

Figure 2: Opposing Outlier Hypothesis

Opposing Outlier Hypothesis

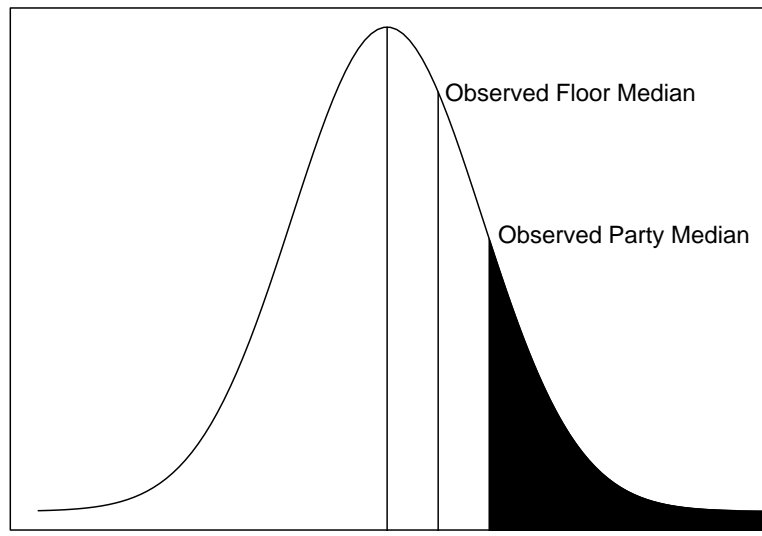

Distribution of 20,000 Simulated Medians

Committees Created Randomly from Party Contingent in House

†Source: Shaded sections are the reported p-values in each table. Small p-values indicate support for the Outlier Hypothesis. 
Figure 3: Representative Committee Hypothesis

Representative Committee Hypothesis

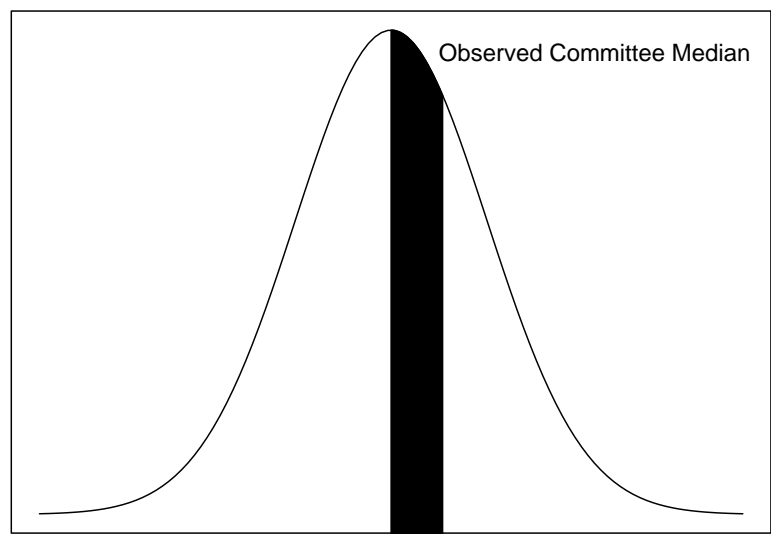

Distribution of 20,000 Simulated Medians

Committees Created Randomly from Entire House

†Source: P-values for this test double the shaded section. Small p-values indicate support for the Representative Committee Hypothesis

Figure 4: Representative Majority-Party Hypothesis

Representative Majority Members Hypothesis

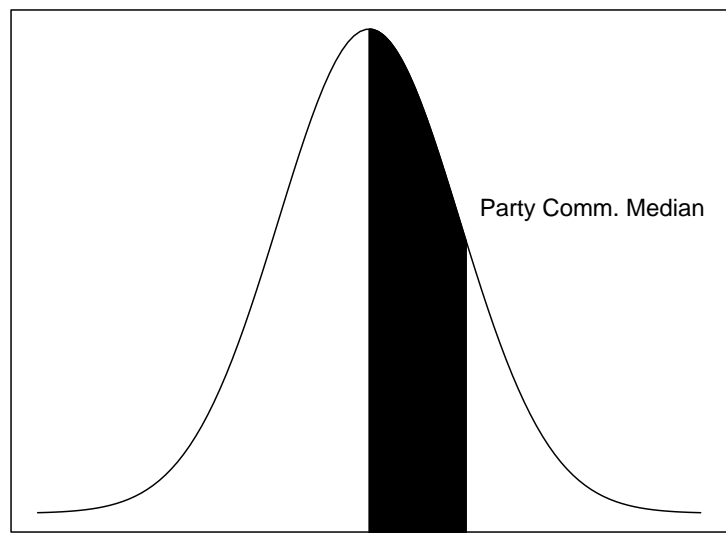

Distribution of 20,000 Simulated Medians

Committees Created Randomly from Majority Party Contingent in House

†Source: P-values for this test double the shaded section. Small p-values indicate support for the Representative Majority-Party Hypothesis 
However, one might expect that in a more evenly divided legislative body, the number of simulated "false" committees would increase. In fact given the more evenly divided partisan composition of the House in the 105th Congress (226 Republicans, 209 Democrats), 39 percent of the committees created are "false" committees. If one were to examine yet a more evenly divided chamber, such as the Senate in the 108th Congress, one generates even a higher proportion of false committees. Using a legislative body with 100 members in which the majority party has 51 seats and the minority party has 49 seats, we simulated 10,000 committees with a committee size of 21.2 Without any restrictions on the simulations, approximately 46 percent of these simulated committees would be controlled by the minority party. These brief examples serve to illustrate how completely random simulations can lead to misrepresentations of the real world. The next question to consider is whether the use of completely random simulations has any substantive effect when used in hypothesis testing.

We re-run Groseclose's analysis with a condition on known party composition to test for alternative results. We argue that simulations must account for real world conditions in testing alternative hypotheses. We also re-run the analysis for a more recent Congress, when party leadership arguably became more important, and when unconstrained simulations are more likely to produce minority-controlled committees. By exploring two different partisan eras in Congress, we allow for theories of Congressional organization to vary over time, and see if such theories are sensitive to asserted periods of "conditional party government." Thus, this paper has both methodological and theoretical importance, in that we expand on Groseclose's Monte Carlo simulations and explore theories of Congressional organization over time.

\section{Replications - 99th Congress (First Session)}

In this section, we replicate and/or expand each hypothesis, using Groseclose's data from the 99th Congress. We specifically perform the following tests:

1. Preference Outlier hypothesis

(a) Replication

(b) Condition on Majority Rules

(c) Condition on Specific Party Ratio

2. Replication of the The Opposing Outlier hypothesis

3. Representative Committee hypothesis

(a) Replication

(b) Condition on Majority Rules

(c) Condition on Specific Party Ratio

\footnotetext{
${ }^{2}$ The average committee size of Senate committees is approximately 21.
} 
Table 1: Outlier Hypothesis - 99th Congress (First Session)

\begin{tabular}{llcccc}
\hline Committee & Rating & $\begin{array}{c}\text { (Original } \\
\text { Findings) }\end{array}$ & Replication & $\begin{array}{c}\text { (Majority } \\
\text { Rules) }\end{array}$ & $\begin{array}{c}\text { (Existing) } \\
\text { Ratio) }\end{array}$ \\
\hline Armed Services & ASC & .000 & .000 & 0 & 0 \\
Appropriations & BIPAC & .089 & .095 & .123 & .062 \\
& CCUS & .020 & .020 & .031 & .008 \\
Budget & BIPAC & .431 & .423 & .512 & .545 \\
Education and Labor & CCUS & .460 & .462 & .555 & .593 \\
& COPE & .077 & .076 & .102 & .029 \\
& IBT & .238 & .242 & .294 & .161 \\
Foreign Affairs & MNPL & .206 & .206 & .250 & .128 \\
Interior & RLEA & .264 & .265 & .328 & .167 \\
& NEA & .431 & .424 & .511 & .372 \\
ASC & .068 & .068 & .096 & .036 \\
Public Works & CCUS & .177 & .176 & .214 & .219 \\
& LCV & .591 & .538 & .608 & .698 \\
& PCCW & .632 & $.437 *$ & .508 & .597 \\
CCUS & .470 & .467 & .551 & .320 \\
Small Business & LCV & .475 & .488 & .415 & .572 \\
Agriculture & PCCW & .394 & .393 & .324 & .468 \\
Aging & RLEA & .591 & .577 & .675 & .496 \\
\hline
\end{tabular}

†Note: * indicates values not replicated in Groseclose (1994).

4. Replication of Representative Democratic Members hypothesis

The tables reported contain Groseclose's findings, our replication results, and the additional tests when conditioning on party composition.

In the replications of Groseclose's first two tests, we were able to reproduce his numbers in all but two cases. In Table 1, the replication of the PCCW/Interior committee is slightly off. In Table 3, the PCCW/Interior committee is drastically different. Both discrepancies are explained with a coding error. Groseclose used a PCCW score of 70 for the Republican median on the Interior committee when the actual score was 7 . This change results in a significantly different result for the committee, though his conclusion (that the hypothesis is not supported overall) is not affected.

We replicated the Representative Committee Hypothesis in all but two cases, with the Interior/PCCW case explained by the same coding error described above. The second discrepancy requires more detailed explanation. Groseclose outlines his test for this hypothesis as comparing the actual committee median to the floor median. In cases where the actual 
Table 2: Democratic Outlier Hypothesis - 99th Congress (First Session)

\begin{tabular}{llcc}
\hline Committee & Rating & Original Findings & Replication \\
\hline Armed Services & ASC & 1 & 1 \\
Appropriations & BIPAC & .220 & .219 \\
& CCUS & .087 & .089 \\
Budget & BIPAC & .470 & .477 \\
Education and Labor & CCUS & .765 & .769 \\
& COPE & .238 & .242 \\
& IBT & .668 & .665 \\
& MNPL & .270 & .266 \\
Foreign Affairs & RLEA & .518 & .518 \\
Interior & NEA & .485 & .486 \\
& ASC & .453 & .463 \\
Public Works & CCUS & .078 & .080 \\
& LCV & .001 & .003 \\
& PCCW & .428 & .437 \\
CCUS & .288 & .283 \\
Small Business & LCV & .851 & .858 \\
Agriculture & PCCW & .662 & .660 \\
Aging & RLEA & .518 & .516 \\
\hline
\end{tabular}

$\dagger$ †ote: * indicates values not replicated in Groseclose (1994).

committee median is greater than the floor median, Groseclose subtracts .5 of the simulations and doubles the remaining proportion. This avoids making the assumption that an equally distant committee median (but on the other side of the floor median) is "as far away" as the actual median. For example, imagine a floor median of 50 and a committee median of 55. Groseclose finds the proportion of committees less than 55 (i.e., 0.65), subtracts out 0.5 (leaving 0.15), and doubles the proportion (a final p-value of 0.3). In cases where the actual median is less than the floor median, he finds the proportion of simulations greater than the committee median, subtracts 0.5 , and doubles the remaining amount.

However, in cases where the actual committee is greater than the floor, but bothare less than the median of the 20,000 simulations, the subtraction of .5 the simulations produces a negative p-value. Thus, consider the situation where only 0.49 of the simulations lie below the example of 55 above. By subtracting .5, the remaining proportion doubled is -0.02 .

In the change, we compared the actual committee median with the median of the 20,000 medians, which is truly a test of how far away the actual is from the hypothesis of committees randomly generated from the floor. This change in the set-up exactly replicated Groseclose's numbers in all but two cases. Why? In almost all the cases, the actual floor median equaled 
Table 3: Republican Outlier Hypothesis - 99th Congress (First Session)

\begin{tabular}{llcc}
\hline Committee & Rating & Original Findings & Replication \\
\hline Armed Services & ASC & .698 & .701 \\
Appropriations & BIPAC & 1 & .999 \\
& CCUS & .999 & .999 \\
Budget & BIPAC & .101 & .102 \\
Education and Labor & CCUS & .086 & .083 \\
& COPE & .878 & .872 \\
& IBT & .985 & .985 \\
MNPL & .940 & .941 \\
Foreign Affairs & RLEA & .584 & .597 \\
Interior & NEA & .957 & .958 \\
& ASC & .757 & .756 \\
Public Works & CCUS & .550 & .569 \\
& LCV & .020 & .020 \\
& PCCW & 1 & $.024 *$ \\
& CCUS & .727 & .757 \\
Small Business & LCV & .552 & .553 \\
Agriculture & PCCW & .924 & .930 \\
Aging & RLEA & .739 & .716 \\
\hline
\end{tabular}

$\dagger$ †ote: * indicates values not replicated in Groseclose (1994).

the median of the 20,000 simulations, effectively making his set-up and our change nothing but stylistic. Nonetheless, in the second discrepancy from Table 4, the actual committee median equals the median of the 20,000 simulations, meaning the p-value reported (in the replication column) is the proportion of simulations equal to the actual floor median; in Groseclose's test of this committee/IG dyad, the committee median is slightly larger than the floor median, making his test in this case slightly different than ours.

The change in set-up has greater implications for our conditioned simulations. In those cases, the condition on majority rule and exact proportion no longer makes it likely that the median of the simulations will match the median of the floor. Thus, there is a greater chance that the test as specified in the original article will produce a negative p-value. Our change in the test set-up corrects for this possibility. Despite these changes, however, Groseclose's original findings still hold.

Finally, in Table 5, we present our attempts to replicate Groseclose's test of the Representative Democratic Members Hypothesis. The last column lists our results based on data we collected independently from Groseclose, since we did not initially receive the original data for this hypothesis. For most of the committees we were unable to exactly replicate 
Table 4: Representative Committee Hypothesis - 99th Congress (First Session)

\begin{tabular}{llcccc}
\hline Committee & Rating & $\begin{array}{c}\text { (Original } \\
\text { Findings) }\end{array}$ & Replication & $\begin{array}{c}\text { (Majority } \\
\text { Rules) }\end{array}$ & $\begin{array}{c}\text { (Existing) } \\
\text { Ratio) }\end{array}$ \\
\hline Armed Services & ASC & 1 & 1 & 1 & 1 \\
Appropriations & BIPAC & .837 & .834 & .768 & .896 \\
& CCUS & .974 & .973 & .954 & .991 \\
Budget & BIPAC & .249 & .252 & .064 & .076 \\
Education and Labor & CCUS & .149 & .150 & .089 & .165 \\
& COPE & .891 & .893 & .853 & .964 \\
& IBT & .955 & .951 & .932 & .986 \\
Foreign Affairs & MNPL & .639 & .628 & .543 & .783 \\
Interior & RLEA & .561 & .550 & .453 & .753 \\
& NEA & .991 & .989 & .506 & .999 \\
ASC & .930 & .931 & .902 & .970 \\
Public Works & CCUS & .779 & .784 & .730 & .764 \\
& LCV & .141 & .139 & .146 & .387 \\
& PCCW & .736 & $.267^{*}$ & .074 & .095 \\
& CCUS & .104 & .100 & .104 & .412 \\
Small Business & LCV & .208 & .188 & .320 & .098 \\
Agriculture & PCCW & .272 & .261 & .422 & .158 \\
Aging & RLEA & .224 & .218 & .239 & .601 \\
\hline
\end{tabular}

†Note: * indicates values not replicated in Groseclose (1994).

his findings, although the substantive findings still hold. This is because the original ADA scores used by Groseclose were compiled by Legi-Slate, which did not penalize members for absences. Furthermore, the committee assignments we used were slightly different since we compiled committee assignments from the Almanac of American Politics, which did not reflect 14 committee assignment changes. 3

After obtaining the data used by Groseclose, we were able to replicate, for the most part, Groseclose's original findings. ${ }^{4}$ We found slightly different results for only two of the committees. An interesting point of note is that the Legi-Slate ADA scores are non-integers as a result of their method of accounting for members' absences. Whether one uses the rounded off or non-integer values makes little difference in the results, except for a noticeable

\footnotetext{
${ }^{3}$ In our independent collection of ADA data, we were unable to find committee assignments for two members of the 99th Congress: Catherine Long (LA-8), who took over for her husband, William Long, after he died; and Francis McCloskey (IN-8), reelected to the Ninety-ninth Congress pursuant to H. Res. 146, May 1, 1985.

${ }^{4}$ We especially want to thank Keith Krehbiel for retrieving this original data and converting it for us.
} 
Table 5: Representative Democratic Members Hypothesis - 99th Congress (First Session)

\begin{tabular}{lccccc}
\hline Committee & Rating & Original & $\begin{array}{c}\text { Replication } \\
\text { (No Rounding) }\end{array}$ & $\begin{array}{c}\text { Replication } \\
\text { (Rounding) }\end{array}$ & "Scratch" \\
\hline Appropriations & ADA & .508 & .496 & .531 & $.729^{*}$ \\
Energy and Commerce & ADA & .106 & $.155^{*}$ & $.257^{*}$ & $.229^{*}$ \\
Rules & ADA & .825 & .839 & .826 & $.983^{*}$ \\
Ways and Means & ADA & .297 & .325 & .276 & $.353^{*}$ \\
Science and Technology & ADA & .946 & .940 & .937 & .967 \\
Public Works & ADA & .452 & .477 & .498 & $.965^{*}$ \\
Post Office & ADA & .953 & .950 & .962 & .931 \\
Veteran's Affairs & ADA & .925 & .966 & .966 & $.988^{*}$ \\
House Administration & ADA & .558 & .534 & .524 & $.421^{*}$ \\
Government Reform and Oversight & ADA & .102 & $.156^{*}$ & $.217^{*}$ & $.302^{*}$ \\
\hline
\end{tabular}

†Note: * indicates values not replicated in Groseclose (1994).

difference in the aforementioned committees.

\section{Extensions - 105th Congress (First Session)}

We next expand on Groseclose's analysis by examining an additional Congress with a more evenly divided House. We do so for both methodological and substantive reasons. Methodologically, the more even partisan split of the last few Congresses implies that simulations not conditioned on party composition will very likely produce simulated committees with more minority party members than majority party members. Substantively, this is a critical empirical question to assess whether the relevance of political parties to committee organization varies over time, as proponents of conditional party government assert, or whether it even matters at all, as proponents of a "partyless" Congress might argue.

Thus, we extend Groseclose's analysis by examining the same four hypotheses for the 105th Congress. What follows below are the same tables as in the previous section, but with the simulation results for the more recent Congress. Table 6 notes relevant name changes in committees from the 99th to the 105th. We were unable to collect all interest group scores from the original Groseclose article, so we only perform the tests for four interest groups on five committees.

The last hypothesis applies to the majority party committee in Congress. Thus, to extend it to the 105th, we run the analysis for the Republican contingent on each committee. The extensions to the 105th do not conflict with Groseclose's conclusions from the 99th. There is little evidence in these data that support the stated theories of congressional organization. 
Table 6: Relevant Committee Name Changes From 99th to 105th

\begin{tabular}{ll}
\hline Committee (99th) & Committee (105th) \\
\hline Armed Services & National Security \\
Education and Labor & Education and the Workplace \\
Foreign Affairs & International Relations \\
Interior & Resources \\
Public Works & Transportation and Infrastructure \\
\hline
\end{tabular}

†Source:

http://web.mit.edu/17.251/www/data_page.html

Table 7: Outlier Hypothesis

\begin{tabular}{llcccc}
\hline Committee & Rating & $\begin{array}{c}\text { 99th } \\
\text { (Groseclose) }\end{array}$ & 105th & $\begin{array}{c}\text { (Majority } \\
\text { Rules) }\end{array}$ & $\begin{array}{c}\text { (Existing } \\
\text { Ratio) }\end{array}$ \\
\hline Appropriations & CCUS & .020 & .291 & .486 & .544 \\
Budget & CCUS & .460 & .367 & .565 & .555 \\
Education and the Workplace & COPE & .077 & .361 & .630 & .679 \\
& NEA & .431 & .404 & .715 & .802 \\
Resources & CCUS & .177 & .309 & .515 & .510 \\
\multirow{5}{*}{ Transportation and Infrastructure } & LCV & .591 & .007 & .012 & .005 \\
& CCUS & .470 & .280 & .451 & .460 \\
& LCV & .475 & .390 & .552 & .579 \\
\hline
\end{tabular}

\section{Conclusion}

The evidence reported here, even with specified restrictions and extensions, do not appear to support commonly asserted theories of congressional organization. What are we to make of this? Consider the partisan theories of Congressional organization. The null results presented above do not necessarily mean that party is not useful in understanding Congressional committee organization. For example, in cases where the electorate returns a Congress with polarized party members, and when the leadership wishes to stack important committees with partisan outliers, party leaders can sample randomly from their membership, making the null results consistent with partisan theories of Congressional organization.

More broadly, however, the null results suggest the need for:

1. Better alternative theories;

2. Alternative measures of member preferences than interest group scores; 
Table 8: Democratic Outlier Hypothesis

\begin{tabular}{llcc}
\hline Committee & Rating & 99th (Groseclose) & 105th \\
\hline Appropriations & CCUS & .087 & .099 \\
Budget & CCUS & .765 & .697 \\
Education and the Workplace & COPE & .238 & .967 \\
& NEA & .485 & .926 \\
Resources & CCUS & .078 & .616 \\
\multirow{5}{*}{ Transportation and Infrastructure } & LCV & .001 & .285 \\
& CCUS & .288 & .694 \\
& LCV & .851 & .996 \\
\hline
\end{tabular}

Table 9: Republican Outlier Hypothesis

\begin{tabular}{llcc}
\hline Committee & Rating & 99th (Groseclose) & 105th \\
\hline Appropriations & CCUS & .999 & .911 \\
Budget & CCUS & .086 & .850 \\
Education and the Workplace & COPE & .878 & .722 \\
& NEA & .957 & .080 \\
Resources & CCUS & .550 & 1 \\
\multirow{2}{*}{ Transportation and Infrastructure } & LCV & .020 & .123 \\
& CCUS & .727 & .935 \\
& LCV & .552 & .983 \\
\hline
\end{tabular}

3. Controls for other constraints, such as seniority, geographic balance, or partisan rules on members' committee portfolios.

Finally, our extensions raise a crucial question with respect to Monte Carlo simulations. Clearly, Groseclose's work is a much more accurate test of these hypotheses than performed by earlier scholars. However, with respect to such simulations, we ask how "random" should "random" be? We have made the case for at least a simple condition on simulations. Of course, with too many restrictions, one could perfectly generate the observed outcomes. So one needs to carefully assess what are the necessary parameters for such hypothesis testing. Thus, a strong theoretical reason for including certain conditions on simulations is necessary in such tests.

\section{References}

Cox, Gary W. \& Matthew D. McCubbins. 1993. Legislative Leviathan: Party Government in the House. Berkeley, CA: University of California Press. 
Table 10: Representative Committee Hypothesis

\begin{tabular}{llcccc}
\hline Committee & Rating & $\begin{array}{c}99 \text { th } \\
\text { (Groseclose) }\end{array}$ & $\begin{array}{c}\text { 105th } \\
\text { (Majority } \\
\text { Rules) }\end{array}$ & $\begin{array}{c}\text { (Existing } \\
\text { Ratio) }\end{array}$ \\
\hline Appropriations & CCUS & .974 & .990 & .982 & .550 \\
Budget & CCUS & .149 & .979 & .546 & .555 \\
Education and the Workplace & COPE & .891 & .534 & .217 & .284 \\
& NEA & .991 & .219 & .421 & .597 \\
Resources & CCUS & .779 & .972 & .492 & .501 \\
& LCV & .141 & .994 & .988 & .995 \\
Transportation and Infrastructure & CCUS & .104 & .997 & .994 & .999 \\
& LCV & .208 & .667 & .308 & .345 \\
\hline
\end{tabular}

Table 11: Representative Majority Members Hypothesis

\begin{tabular}{lccc}
\hline Committee & Rating & $\begin{array}{c}\text { 99th (Groseclose) } \\
\text { (Democrats) }\end{array}$ & $\begin{array}{c}\text { 105th } \\
\text { (Republicans) }\end{array}$ \\
\hline Appropriations & ADA & .508 & .443 \\
Commerce & ADA & .106 & .879 \\
Rules & ADA & .825 & 1 \\
Ways and Means & ADA & .297 & .807 \\
Science & ADA & .946 & .896 \\
Transportation and Infrastructure & ADA & .452 & .999 \\
Veteran's Affairs & ADA & .925 & .194 \\
House Oversight & ADA & .558 & .262 \\
Government Reform and Oversight & ADA & .102 & .889 \\
\hline
\end{tabular}

Gilligan, Thomas \& Keith Krehbiel. 1987. "Collective Decision-Making and Standing Committees: And Informational Rationale for Restrictive Amendment Procedures." Journal of Law, Economics, and Organization 3:287-335.

Gilligan, Thomas \& Keith Krehbiel. 1989. "Asymetric Information and Legislative Rules with a Heterogeneous Committee." American Journal of Political Science 33:459-490.

Gilligan, Thomas \& Keith Krehbiel. 1990. "Organization of Informative Committees by a Rational Legislature." American Journal of Political Science 34:531-564.

Groseclose, Tim. 1994. "Testing Committee Composition Hypotheses for the U.S. Congress." The Journal of Politics 56(2):440-458. 
Weingast, Barry \& William Marshall. 1988. "The Industrial Organization of Congress; or, Why Legislatures, Like Firms, are not Organized as Markets." Journal of Political Economy 96:132-163. 